\title{
Study on the Dynamic Protection of Cultural Relics: A Case Study of the Bell Tower of Jinling High School
}

\author{
Ziyue $\mathrm{Cai}^{1}$, Jinsong $\mathrm{Ma}^{2}$ \\ ${ }^{1}$ Jinling High School, Nanjing, China \\ ${ }^{2}$ School of Geographic and Oceanographic Sciences, Nanjing University, Nanjing, China \\ Email: caiziyue2002@163.com
}

\begin{abstract}
It is an inevitable trend for cultural relics protection to change from static protection to dynamic protection. Based on the protection status of the Bell Tower of Jinling High School, this paper analyzes why the transformation from static to dynamic protection is necessary. Through literature review, questionnaire survey, think-tank consulting and other research methods, using 3D modeling, GIS, Space Syntax and other technical means, this paper puts forward ideas in dynamic protection including introduction of ICOMOS Heritage Alert Template, establishment of Public Open Day, optimization of surrounding landscape of cultural relics, and so on.
\end{abstract}

Keywords: bell tower, cultural relics, static protection, dynamic protection.

\section{Introduction}

Protection of cultural relics is a worldwide topic. There are two types of protection of cultural relics: static protection and dynamic protection. The former pays attention to the physical security of cultural relics, while the latter not only pays attention to the physical security of cultural relics, but also emphasizes on publicizing the historical and cultural background of relics, so as to make cultural relics "alive" once again.

\section{Background}

Built in 1888, the Bell Tower of Jinling High School is a key cultural relic of China, famous for its combination of Chinese architectural style with western architectural style. Once being the highest building in Nanjing, it witnessed the start and development of modern education in China, making it not only an old building but also one with profound cultural value (Chang, 2009).

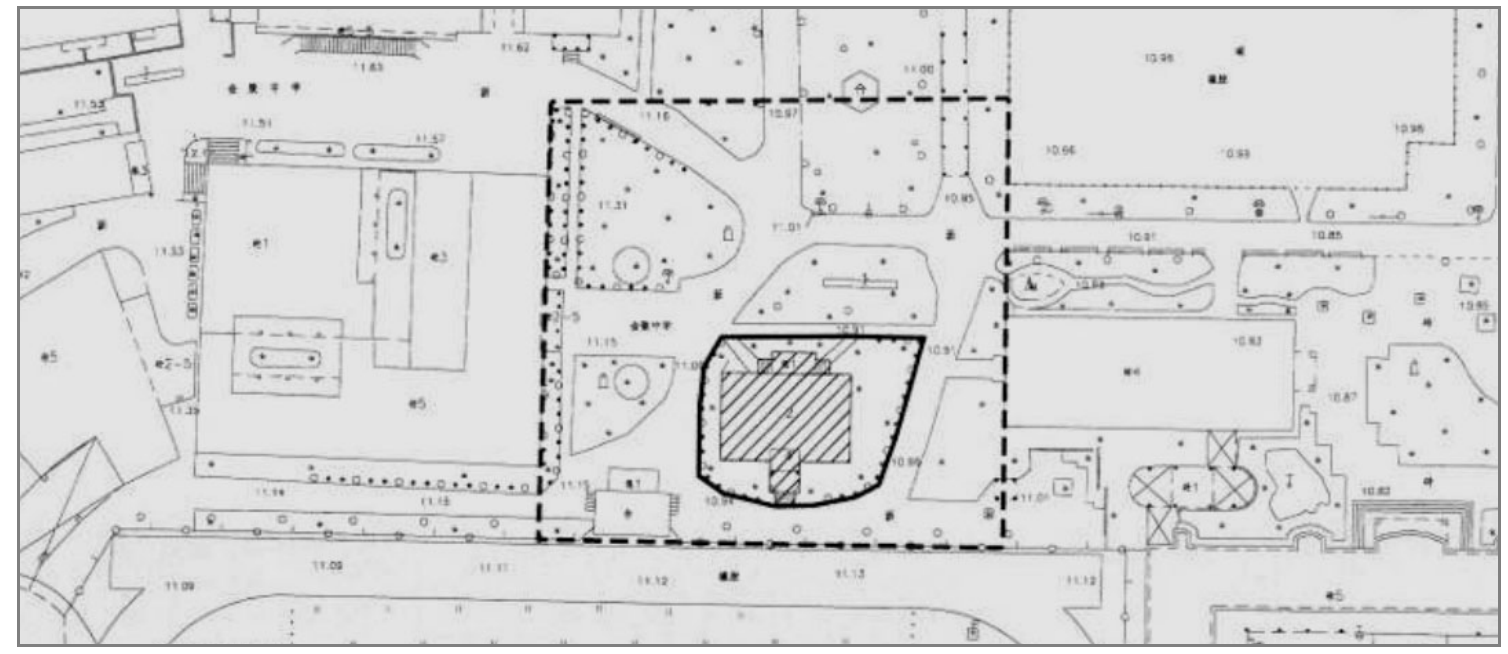

Figure 1. Location of the Bell Tower and its protection scope and construction control zone (Source: Renovation plan for the Bell Tower as the former site of Jinling University) 
Since its completion, protection of the Bell Tower has followed the concept of static protection. In 2010, the Bell Tower underwent an overhaul. At present, it is being used as an office facility. School History Museum is located in the newly built Sports and Art Building, but not in the Bell Tower. Citizens generally know very little about the history behind the Bell Tower or its cultural connotation .
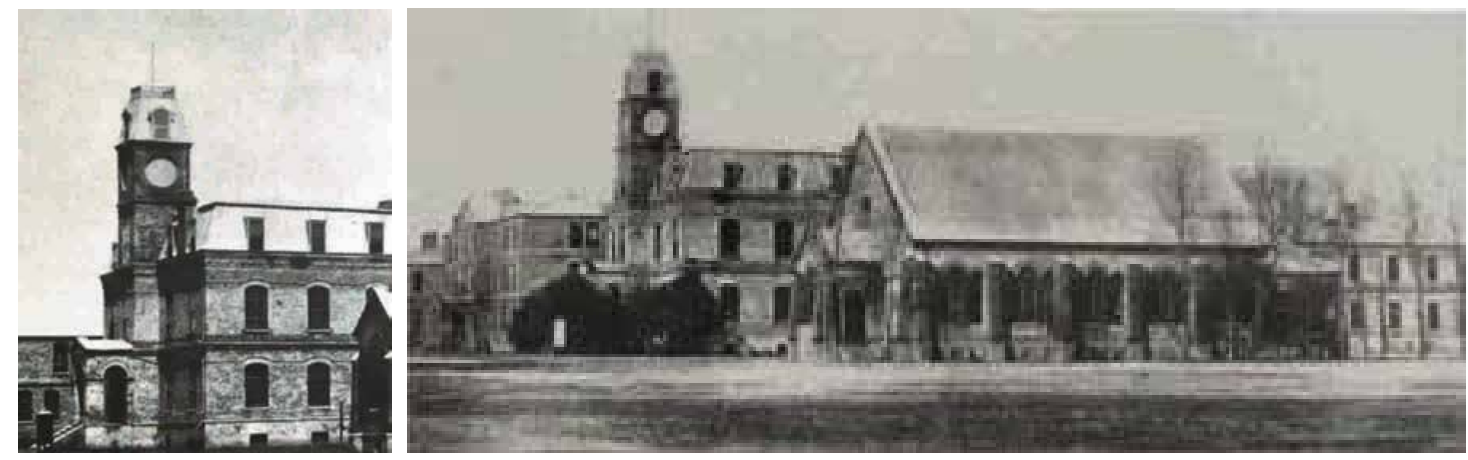

Figure 2. The Bell Tower in 1910

(Source: Internet)

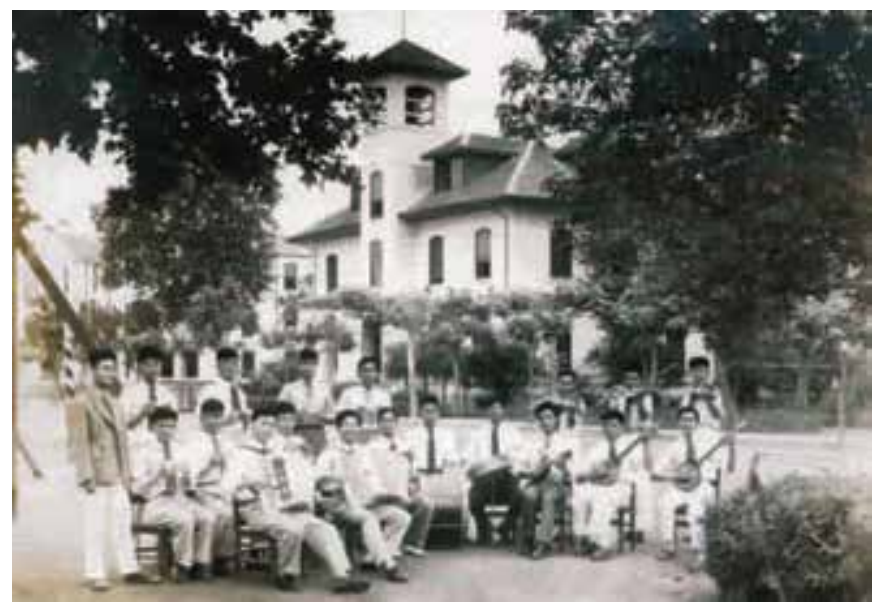

Figure 3. Group photo of overseas Chinese students taken in front of the Bell Tower in 1957

(Source: Internet)

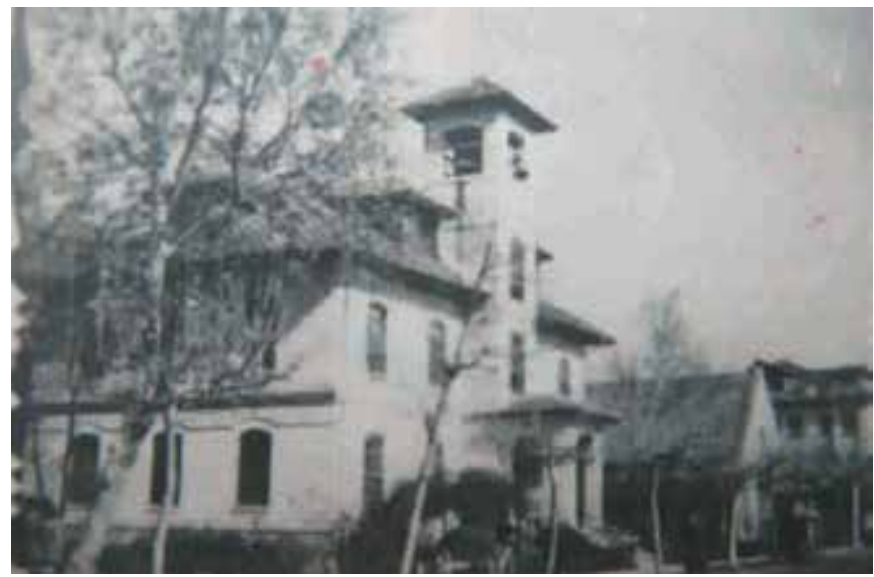

Figure 4. Picture of the Bell Tower used for New Year cards in 1960

(Source: Internet) 


\section{$3 \quad$ Protection Status and Analysis of the Bell Tower}

\subsection{Protection Status}

The Bell Tower is in American architectural style. Originally built to as a five-floor tower, the building was changed to four-floor during reconstruction, and has been retained until now (Chun, 201). 3D modeling of the Bell Tower had been completed through aided design function of SKETCH UP software, which deepened our understanding of architecture vocabulary and construction technology (Lin, 2012). The plane of the Bell Tower is rectangular, having slightly longer east-west ends, with a short corridor layout in the north-south direction. There are entrances and porches in the north and south sides with higher terraces. Wooden stairs are in the middle of the north side. Main body of the building has three floors, and the attic of the third floor is decorated with sloping roof windows. The copper Bell is located in the fourth floor. There are also fireplace and chimney in the main body of the building.
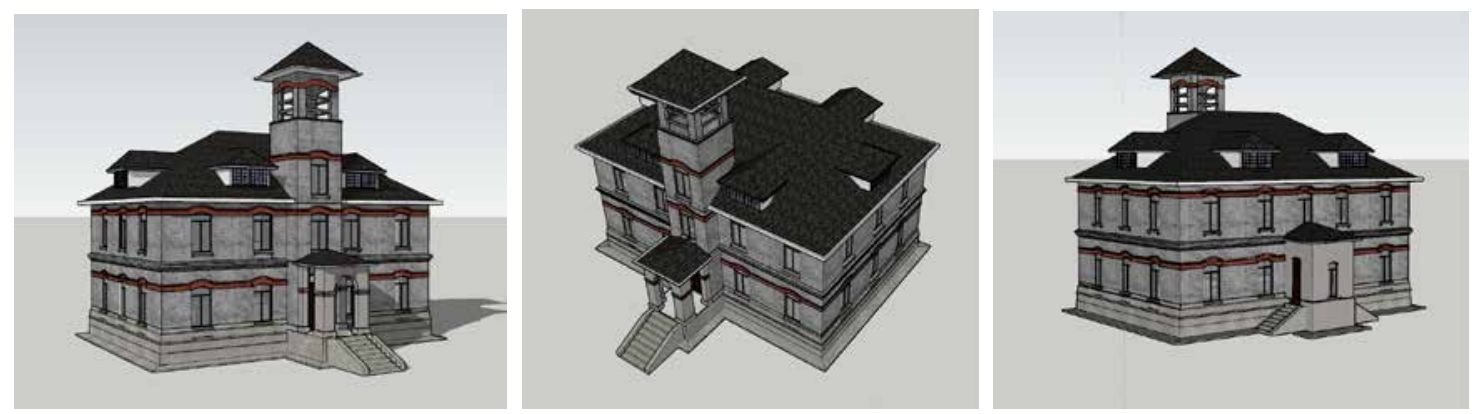

Figure 5. 3D modeling of the Bell Tower

(Source: By author)

The Bell Tower was last renovated in 2010. In recent years, due to the influence of natural factors, doors and windows on the facade and small areas on the roof have been eroded by external media, resulting in material damage. However, the overall structure and appearance of the building are good, and the protection is relatively effective.
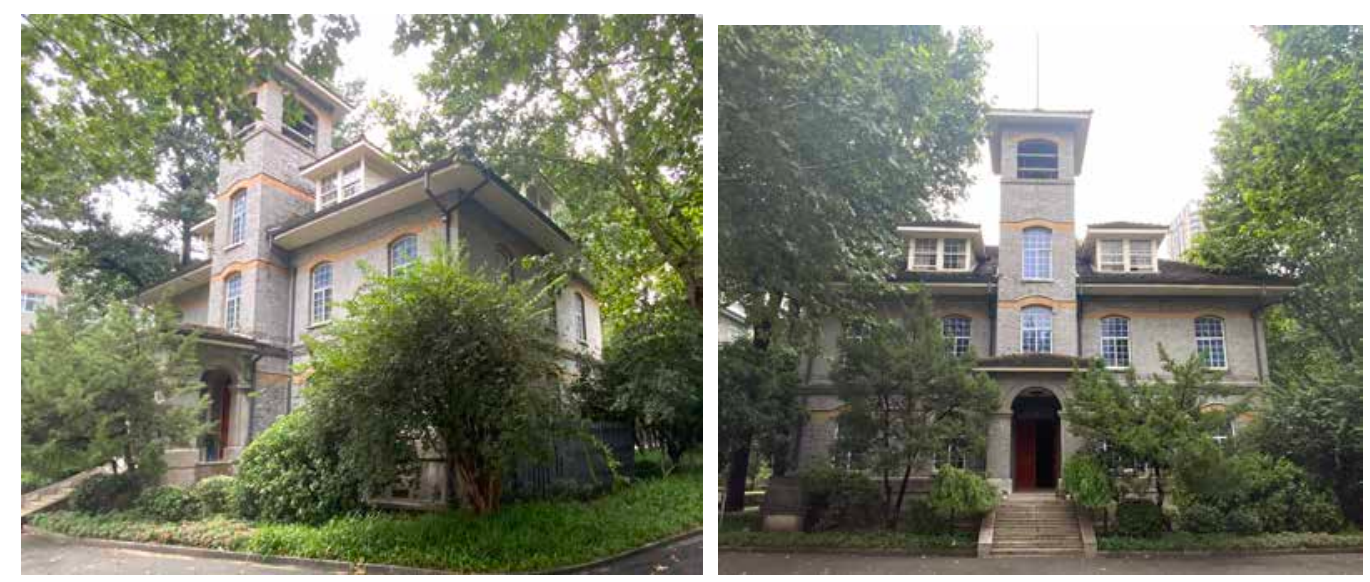

Figure 6. Exterior of the Bell Tower

(Source: By author)

\subsection{Spatial Function Distribution of the Bell Tower}

With the change of time, the internal functions of the Bell Tower have changed many times. After 1993, the Bell Tower was wholly changed into office rooms, mainly fulfilling needs of administration. The users 
were mainly teachers. Students' understanding of the Bell Tower gradually faded away. They only thought it as an old building, having very little understanding of its deep historical and cultural connotation.
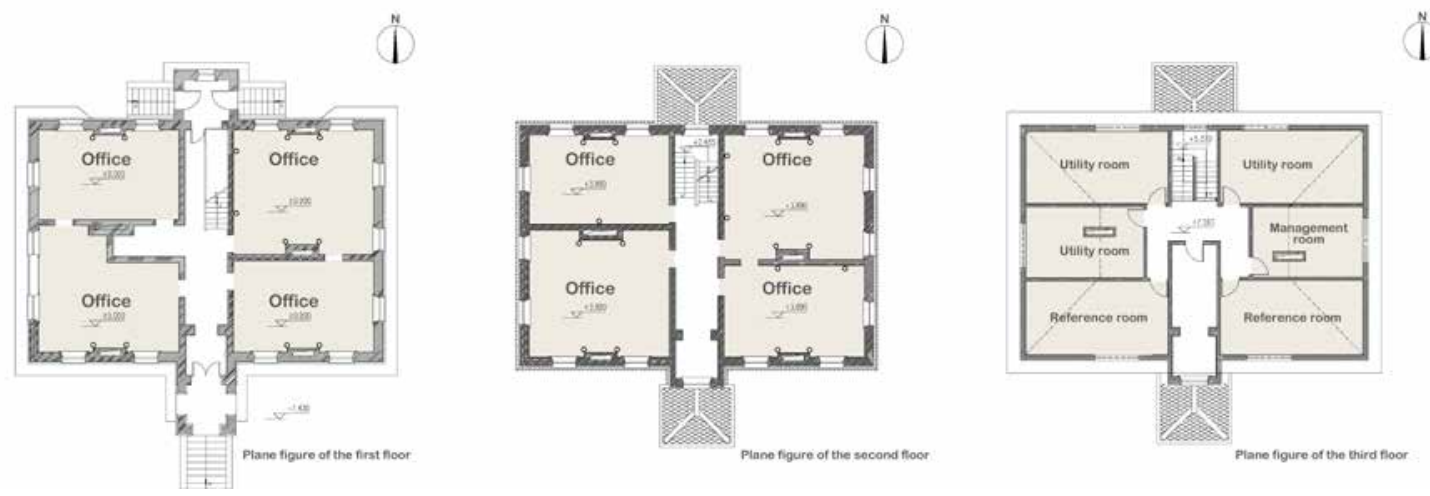

Figure 7. Internal function distribution of the Bell Tower

(Source: By author)

\subsection{Quantitative Analysis of Building's External Space}

Space Syntax is a method used to evaluate the relationship between spaces, combining quantitative analysis and visual analysis. GIS is used to quantitatively analyze the 12-hectare area around the Bell Tower. There are three analysis methods: spatial convenience analysis, simulation analysis of pedestrian flow and spatial viewshed analysis.

Spatial convenience analysis is to judge the degree of spatial integration by inter-visuality calculation in the convex space. Convex space is a space in which any two points can see each other. In convex space, the topological method can be used to judge spatial convenience by connecting buildings in the area. Finally, the higher the integration, the higher the accessibility. As shown in Figure 8, the Bell Tower is located in the red plot. Through the generated axial map, we can see that the north and south sides of the Bell Tower have relatively higher degree of integration, that is, in this space, the spatial accessibility is the best.
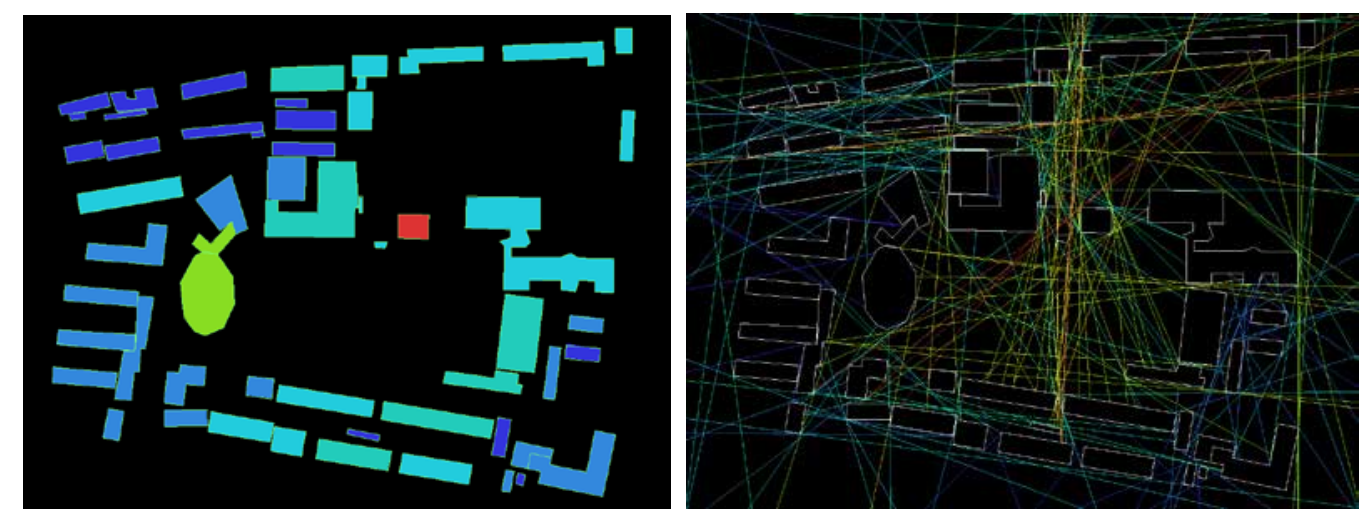

Figure 8. Spatial accessibility analysis

(Source: By author)

The purpose of simulation analysis of pedestrian flow is to obtain spatial hot spots by releasing simulated pedestrian flow in space. As shown in Figure 9, the crowd's activity area is concentrated in the playground on the south side of the Bell Tower and the open space on the north side. Located between pedestrian flow areas, the Bell Tower is the only way for crowd activities. Therefore, the Bell Tower is an important node in the open space of Jinling High School, and also an important building to establish the spatial intention. 
Spatial viewshed analysis is used to understand the degree of spatial awareness and perception, and to grasp the relationship between spatial units by analyzing integration of sight line, aggregation of sight line, control of sight line and link of sight line. As shown in Figure 10, ignoring the influence of landscape elements, the north-south space of the Bell Tower has the highest integration of sight line, with the lowest constriction of sight line. Landscape elements here can not be quantitatively analyzed by softwares. According to field survey, the constriction of sight line on the north is higher, and that on the south is less, with luxuriant vegetations around the Bell Tower.

Combining quantitative analysis with field survey, we know that surrounding spatial conditions of the Bell Tower are ideal. Although there are adverse effects, by optimizing the landscape environment, the Bell Tower itself and surrounding space can have a better environment of sight line. How to make the Bell Tower perceived better by the crowd has become an important challenge for protection and utilization.

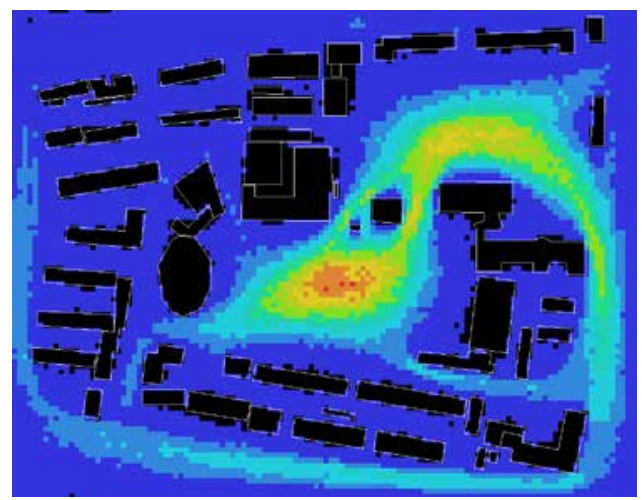

Figure 9. Simulation analysis of pedestrian flow (Source: By author)

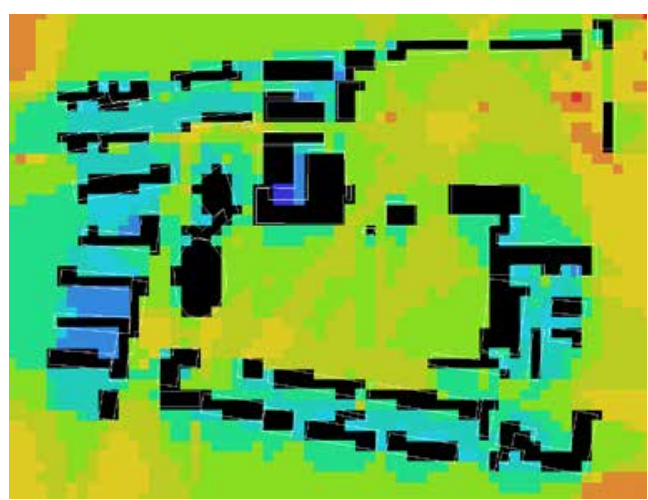

Figure 10. Spatial viewshed analysis (Source: By author)

\subsection{Summary}

As a national key cultural relic, protection measures of the Bell Tower are relatively complete. However, its historical and cultural values are not much known by students and general citizens; the use of internal functions of the building is also too simple. Another problem is that the surrounding environment has made the appearance of the Bell Tower less prominent. These problems are closely related to the concept of static protection.

\section{Analysis of Reasons for Change of Protection Concepts of the Bell}

\section{Tower}

\subsection{Policy Orientation}

In recent years, the government has constantly stressed the need to deal with the relationship between protection and utilization of cultural relics, in order to open up relics to the public. According to relevant policies, social education function of cultural relics should be made full use to meet diversified cultural needs of the masses, enhance national cultural self-confidence, and improve the country's soft power.

\subsection{Public Will}

During the first half of 2020, author of this paper conducted an online questionnaire survey on the Bell Tower. A total of 150 questionnaires were distributed with 127 valid questionnaires recovered. Ages of respondents ranged from 18 to 60 years old, and their educational background ranged from junior high school to doctor. To answer five objective facts about the Bell Tower, $49 \%$ of the respondents said they did not know at all. $63 \%$ of the respondents said they would like to know more about the Bell Tower if they have the opportunity in the future. $47 \%$ of the respondents suggested that protection of the Bell Tower 
should be further strengthened; its functions should be activated and reused, and citizens should be allowed to go into the building.

\subsection{Effective Practice}

France adopts social participation method in protection of ancient buildings. The government encourages people to rent qualified ancient buildings, but there are strict restrictions on the use and transformation of ancient buildings. HKSAR implements the Revitalising Historic Buildings Through Partnership Scheme. Under supervision of the government and professionals, ancient buildings are handed over to social organizations for operation, which could reduce the government's burden, protect ancient buildings' historical and cultural values from damage, and increase public attention to protection and utilization of ancient buildings.

Above factors make the call for dynamic protection of the Bell Tower increasingly strong.

\section{$5 \quad$ On Further Strengthening Dynamic Protection of the Bell Tower}

Starting from upholding the concept of dynamic protection and making the Bell Tower closer to the public, author of this paper puts forward to following ideas.

\subsection{Establishing Repair Mechanism and Early-Warning Mechanism}

The department concerned should repair damaged parts of doors, windows and roofs in time, while respecting principles of building construction, and protecting appearance characteristics of the building.

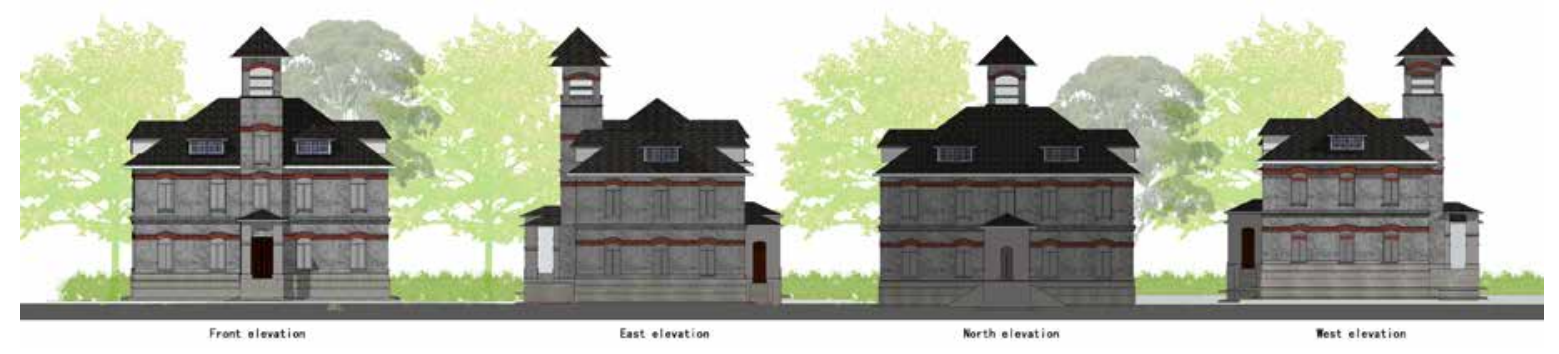

Figure 11. Building elevations of the Bell Tower

(Source: By author)

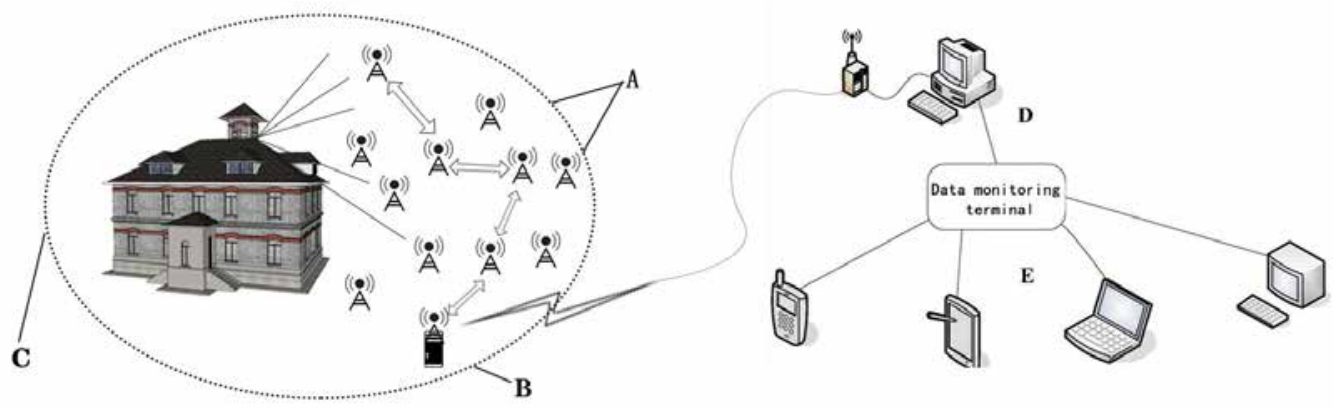

Figure 12. Early-warning system of the Bell Tower

(Source: By author)

In case of emergencies, or facing structural safety problems and hidden damage problems in the cultural relic building, the early-warning system should start automatically. Administrative authority of cultural relics and the school will take timely measures to ensure the safety of the cultural relic. At the same time, 
ICOMOS Heritage Alert Template will be introduced to bring daily management by the school and weekly inspection by the volunteer society for cultural relics protection into the track of unification, standardization and internationalization.

\subsection{Adjusting the Function Distribution inside the Building}

The office function area on the first floor of the Bell Tower will be adjusted to the school cultural exchange function area, and the office function area on the second and third floors will be adjusted to the school history exhibition function area (i.e. School History Museum moved here), as shared spaces for teachers, students, alumni and guests. People will be able to be in closer contact with this historical and cultural carrier, which will integrate cultural experience into people's emotion.

\subsection{Strengthening the Connection of Sight Line between the Bell Tower and Surrounding Space}

By combination of GIS with integrated visibility analysis of Space Syntax, the department concerned should remove landscape vegetations that are destroying the building visibility from the construction control zone of the Bell Tower. Landscape vegetations will be mainly composed of green lawn. At the same time, small leaf boxwood and golden leaf ligustrum, decorated with red maple and begonia could be selected to guide people's attention to the Bell Tower building. By enhancing the connection of sight line with surrounding space, the Bell Tower's spatial symbol and cultural display can be highlighted.
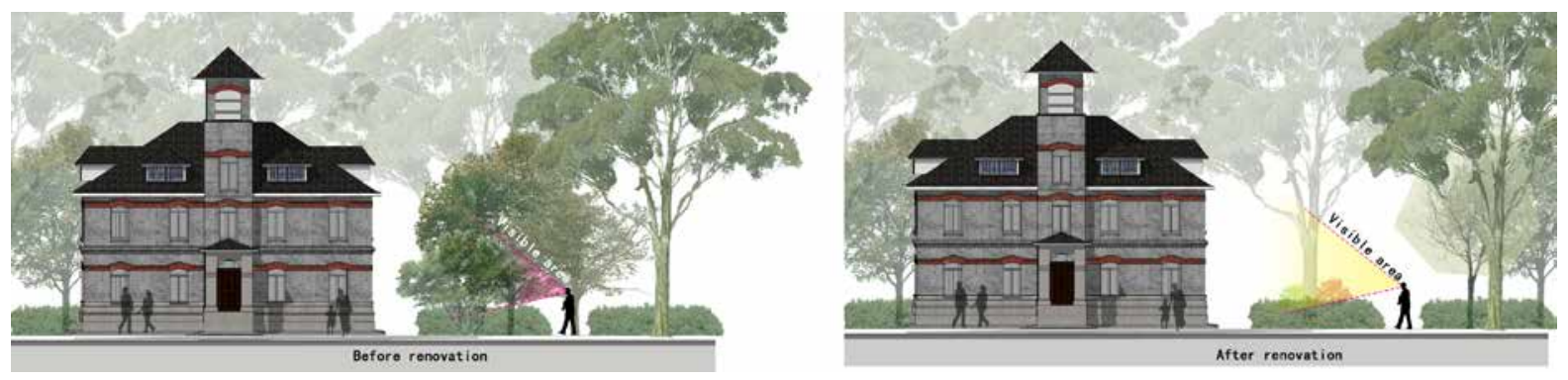

Figure 13. Contrast of connection of sight line between the Bell Tower and surrounding space

(Source: By author)

\subsection{Creating Cultural Perception Scene}

There are a lot of gray spaces in the construction control zone of the Bell Tower. Greening and weeds have gradually occupied the public space, which constantly reduces the scope of activities for teachers and students. Therefore, we should reasonably organize landscape changes around the Bell Tower, and excavate the stock space with the micro renewal method. Seats and landscape architecture can be set up in the construction control zone to create a public space for rest and communication, so as to meet diverse needs of people (Zhou, 2018). Historical figure statues and the culture wall can be established in the entrance area of the building to create a historical atmosphere, also to encourage people to enter the specified situation in advance. 


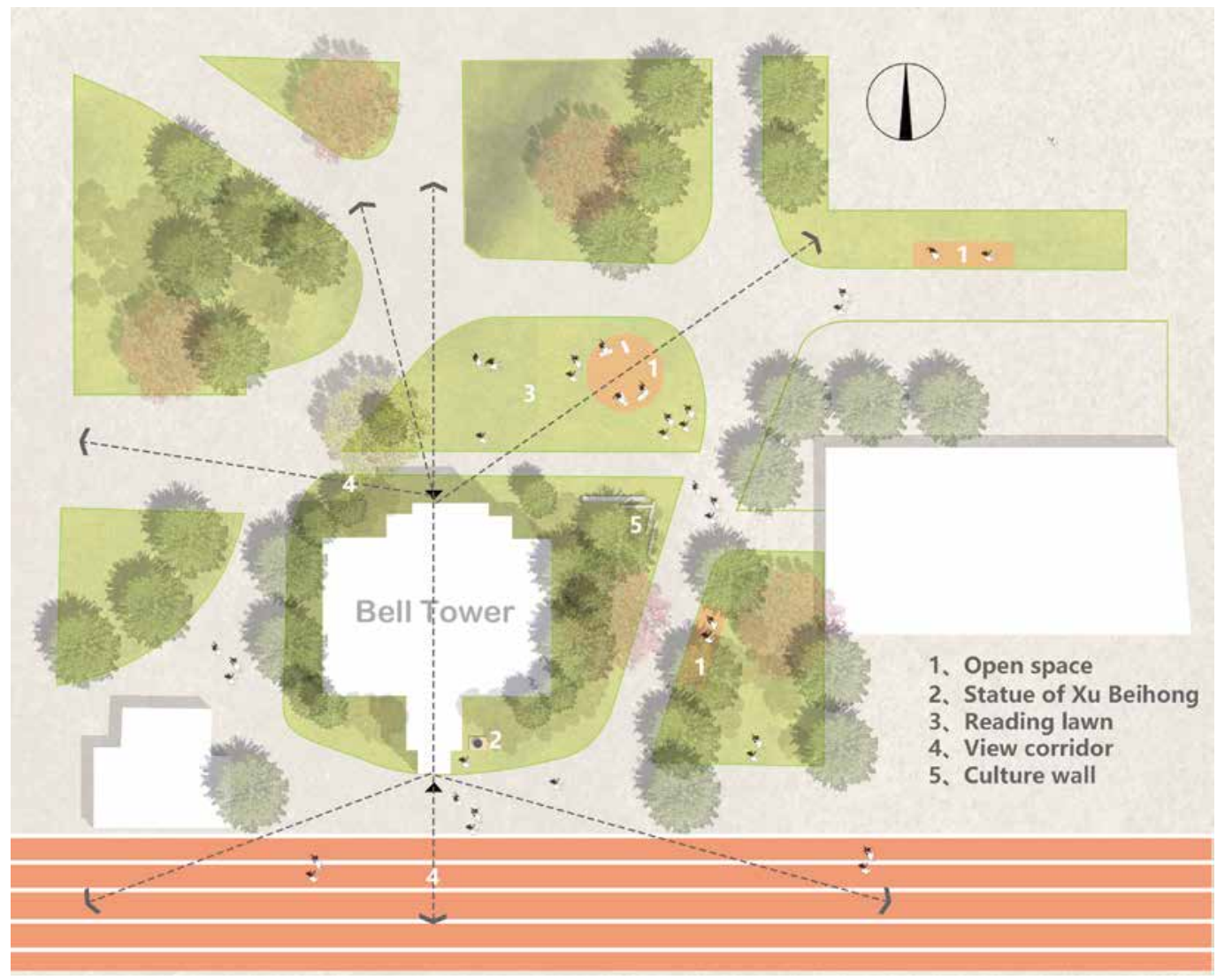

Figure 14. Plane guidance for landscape environment's micro renewal (Source: By author)

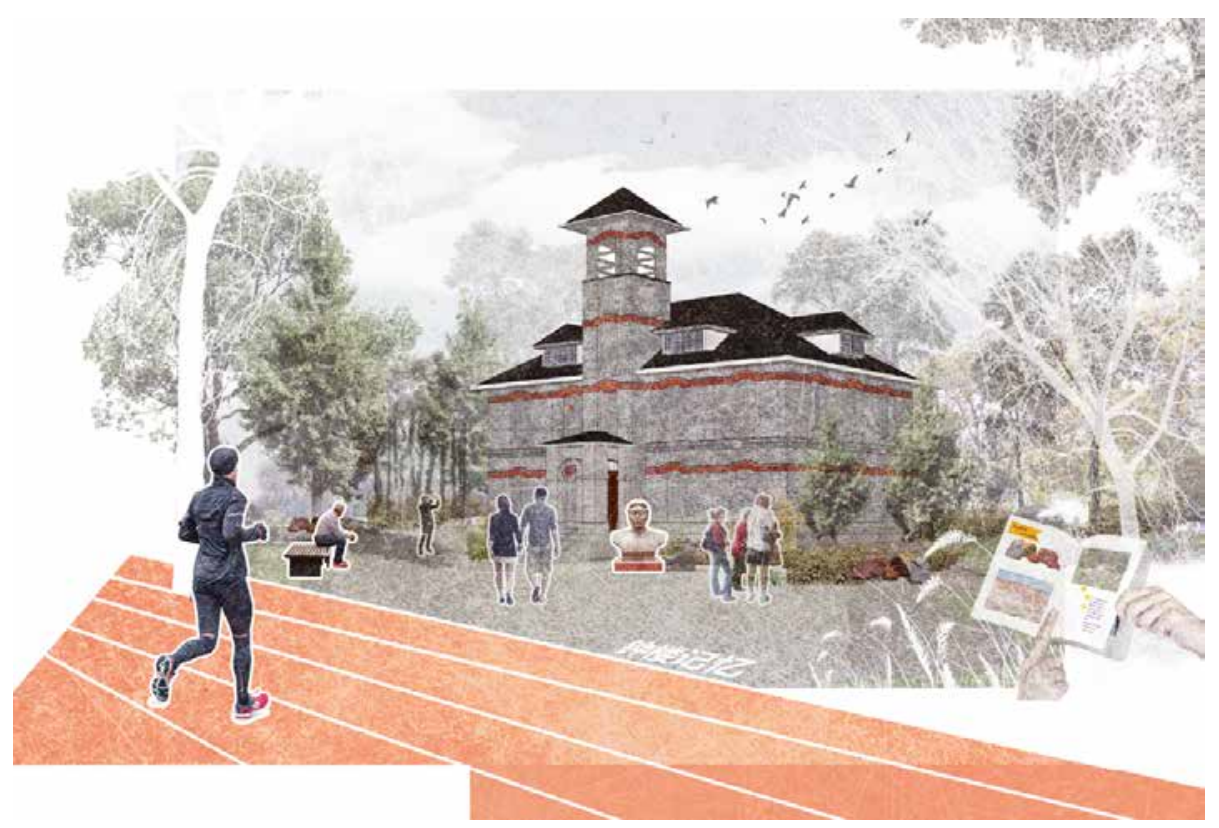

Figure 15. Three dimensional sketch for landscape environment's micro renewal (Source: By author) 


\subsection{Setting Up Public Open Day}

The Bell Tower will be opened to the public one day each year on "Cultural and Natural Heritage Day" or "International Museum Day". The historical and cultural exhibition of the Bell Tower will hopefully leave memories to the public and promote the sense of cultural identity and pride.

\section{Conclusion}

Only by taking dynamic protection measures can the Bell Tower maximize its physical and cultural values, and to be "alive" once again.

\section{References}

1. Chang, Qing, Regeneration of historical environment: Historical consciousness and design exploration. China Construction Industry Press, 2009.

2. Chun, Qing and Huang, Linfa, "Reinforcement and repair design of Bell Tower in Jinling Middle School," Architecture Technology, Vol.43, No.12, pp.1096-1098, 2012.

3. Lin, Yuan, Basic theory of Chinese architectural heritage protection. China Construction Industry Press, 2012.

4. University history compilation group of institute of higher education of Nanjing University, Historical materials of Jinling University. Nanjing University Press, 1989.

5. Zhou, Xueying and Ma, Xiao, Centennial architecture of Nanjing University. Nanjing University Press, 2018. 